\title{
Improving the Reactive Power Compensation Strategy of UPQC
}

\author{
Tongshuo Zhang ${ }^{1,}$, Lixin $\mathrm{Wu}^{1, \mathrm{~b}}$ and Libo $\operatorname{Han}^{1, \mathrm{c}}$ \\ ${ }^{1}$ Institute of Electrical Engineering Chinese Academy of Science, Beijing, China \\ azhangtongshuo@mail.iee.ac.cn, ${ }^{\mathrm{b}}$ wulixin@mail.iee.ac.cn, ${ }^{\mathrm{c}}$ hanlibo@mail.iee.ac.cn
}

Keywords: decoupling control; coordinated control; reactive power; UPQC

Abstract. This paper describes a reactive power control strategy based on the unified power quality conditioner (UPQC). The shunt unit is mainly used to compensate the reactive power based on the active and reactive power decoupling control. Because the series inverter is usually in the bypass switch state, the power coordinated control strategy is also presented. Using series/shunt unit together to compensate reactive power, we can reduce the capacity of shunt inverter. The simulation proved that the control method not only can compensate the active power on the premise of ensuring the system stability, but also can guarantee the stability of the load voltage.

\section{Introduction}

The significance of reactive power compensation is to reduce the capacity of the power supply equipment, improve the power factor of power grid, reduce the wastage of the power grid, and improve the transmission capacity. With the development of science and industry, especially the high-tech industry has urgent demand for the improvement of power quality. UPQC is a kind of power quality management device based on the modern power electronic technology, and it combines the advantage of the dynamic voltage restorer (DVR) and static synchronous compensator (STACOM) ${ }^{[1]}$. The shunt unit can compensate for the reactive power and harmonic of the load to ensure the power quality. At the same time, when the power grid voltage drop or three-phase imbalance happen, the series unit can guarantee the stability of the load voltage. The topological structure is shown in Fig.1.

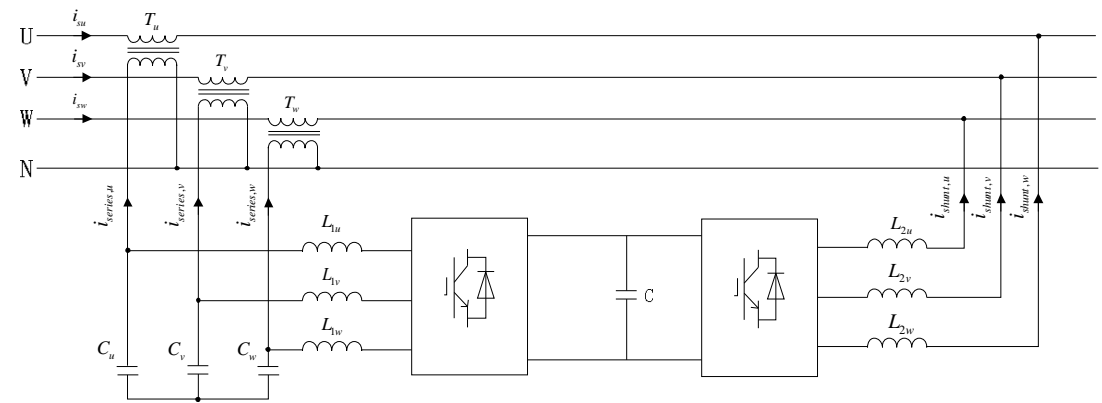

Fig.1 The topological structure of UPQC

In most cases, the grid voltage is stable, and the series unit stays in a bypass status for a long time. But the shunt unit is usually in busy state. This results in the system resources unable to be fully used. This article proposed a reactive power compensation strategy to solve the above problem. Firstly, it presents the active and reactive power decoupling control based on the shunt unit, and then takes use of the series unit to compensate part of the reactive power based on the coordinated control. This strategy will reduce the capacity of shunt unit, and improve the utilization rate of the system.

\section{The Reactive Power Compensation Control Strategy}

A. The Shunt Unit

The shunt unit is mainly used to compensate the reactive power needed by the load, reduce the harmonics caused by the load, and improve the power quality of the grid $^{[2-5]}$.

In ideal conditions, the shunt unit is equivalent to a voltage source, and its equivalent circuit in the three-phase coordinate system is shown in Fig. 2 


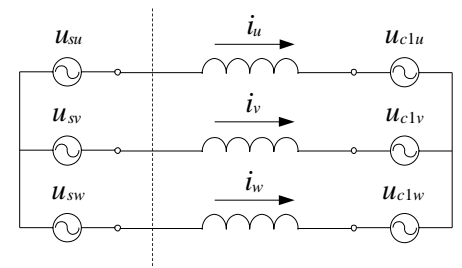

Fig.2 The equivalent circuit

So the voltage equations are as following:

$$
\left\{\begin{array}{l}
u_{s u}-u_{c 1 u}=p \psi_{u} \\
u_{s v}-u_{c 1 v}=p \psi_{v} \\
u_{s w}-u_{c 1 w}=p \psi_{w}
\end{array}\right.
$$

where, $u_{s u, v, w}$ are grid phase voltage, $u_{c 1 u, c 1 v, c 1 w}$ are the output voltage of shunt unit, $\psi_{u, v . w}$ are the magnetism chain of inductances, $p$ is differential divisor.

Take the $u$ phase for example, we could get the equivalent relation through the dq coordinate transformation:

$$
\left\{\begin{array}{l}
u_{s u=}=\sqrt{2 / 3}\left(u_{s d} \cos \theta+u_{s q} \sin \theta\right) \\
u_{c 1 u}=\sqrt{2 / 3}\left(u_{c 1 d} \cos \theta-u_{c 1 q} \sin \theta\right) \\
\psi_{u}=\sqrt{2 / 3}\left(\psi_{s d} \cos \theta-\psi_{s q} \sin \theta\right)
\end{array}\right.
$$

where, $u_{s d, s q}$ are the dq component of the grid voltage, $u_{c 1 d, q}$ are the dq component of shunt unit, $\psi_{s q, s q}$ are the dq component of the magnetism chain.

From (1) and (2), the relationship between the grid and the shunt unit could be represented as

$$
\left(u_{s d}-u_{c 1 d}-p \psi_{s d}+\psi_{s q} p \theta\right) \cos \theta-\left(u_{s q}-u_{c 1 q}-p \psi_{s q}-\psi_{s d} p \theta\right) \sin \theta=0
$$

Assume $p \theta=\omega_{d q}$, and $\omega_{d q}$ is the angular velocity. Because of the grid voltage orientation control, $\omega_{d q}=\omega$ is a variable quantity, and the voltage relationship is as following:

$$
\left\{\begin{array}{l}
u_{s d}-u_{c 1 d}=p \psi_{s d}-\omega_{d q} \Psi_{s q} \\
u_{s q}-u_{c 1 q}=p \psi_{s d}+\omega_{d q} \Psi_{s d}
\end{array}\right.
$$

According to above, the output can be written as

$$
\left[\begin{array}{l}
u_{\mathrm{d}}{ }^{*} \\
u_{\mathrm{q}}{ }^{*}
\end{array}\right]=\left[\begin{array}{l}
u_{\mathrm{sd}} \\
u_{\mathrm{sq}}
\end{array}\right]-\left[\begin{array}{cc}
0 & -\omega \mathrm{L} \\
\omega \mathrm{L} & 0
\end{array}\right]\left[\begin{array}{l}
i_{\mathrm{d}} \\
i_{\mathrm{q}}
\end{array}\right]-K_{p}\left[\begin{array}{c}
i_{\mathrm{d}}{ }^{*}-i_{\mathrm{d}} \\
i_{\mathrm{q}}{ }^{*}-i_{\mathrm{q}}
\end{array}\right]-K_{i}\left[\left[\begin{array}{c}
i_{\mathrm{d}}{ }^{*}-i_{\mathrm{d}} \\
i_{\mathrm{q}}{ }^{*}-i_{\mathrm{q}}
\end{array}\right] \mathrm{d} t\right.
$$

Where, $u_{d, q}{ }^{*}$ are modulating signals, $i_{d, q}{ }^{*}$ are the active current and reactive current, $K_{p, i}$ are the parameters of the current loop.

From (5) we can get the modulating signals of the shunt unit, and we can adjust the active power and the reactive power separately. Thus the control block diagram is shown as Fig.3. 


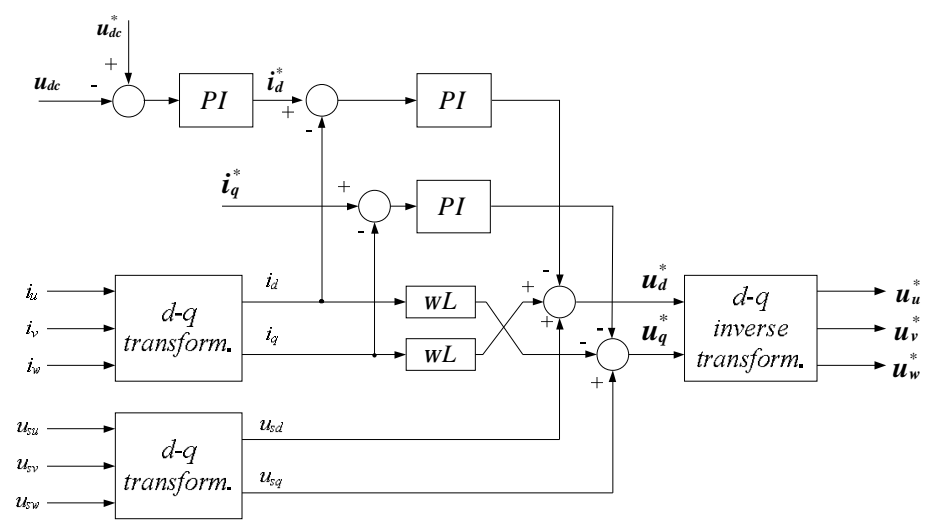

Fig.3 The active and reactive power decoupling control

\section{B. The Series Unit}

In the case of voltage fluctuation, the output of the series unit superposes the network voltage quickly to keep the voltage of the load stable ${ }^{[6]}$. Normally, the control strategies of the series are simple. Feedback control has strong load adaptability, but the design is complex, especially the compensation is more susceptible to the control parameters. Feedforward control has advantages of fast response, simple control, thus this paper choose the feedforward control. The control strategy is shown in Fig.4.

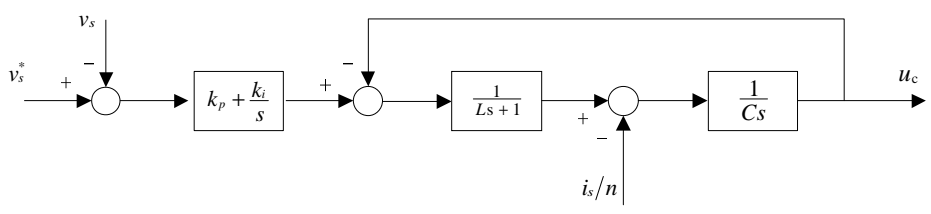

Fig.4 Feedforward control

Most of the time, the grid is in a stable state, and it is means that the series unit is usually stay in the bypass. But on the contrary, the shunt unit is always overloaded. And the status switching caused by voltage fluctuation causes overcurrent protection easily. In order to use resources reasonably, this paper introduces the power flow coordination control ${ }^{[7-9]}$.

Assume the grid stay in normal, the system provides reactive power to the load. As shown in Fig.5, before adding the power flow coordination control, $u_{s}$ is the grid voltage, $i_{L}$ is the load current. And after adding the control, $u_{C}$ is the output of the series unit, $u_{L}$ is load voltage.

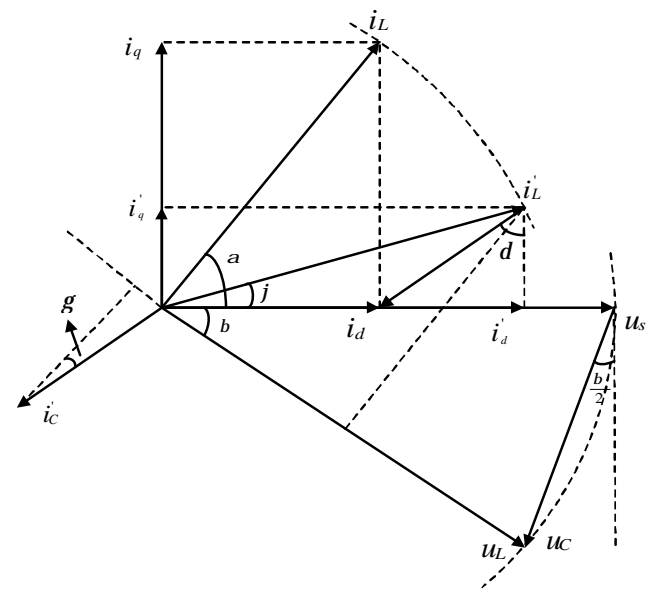

Fig.5 The power flow coordination control

If $U=\left|\hat{u_{s}}\right|, I=\left|\hat{i_{L}}\right|$, the output voltage is

$$
\hat{u_{C}}=2 U \sin \frac{\beta}{2} \angle\left(-\frac{\pi}{2}-\frac{\beta}{2}\right)
$$


Thus, the active power and the reactive power of the series are

$$
\left\{\begin{array}{l}
P=\left|\hat{u_{C}}\right| \sin \frac{\beta}{2}\left|\hat{i_{L}}\right| \cos \varphi=-U I(1-\cos \beta) \cos \alpha \\
Q=\left|\hat{u_{C}}\right| \cos \frac{\beta}{2}\left|\hat{i_{L}}\right| \sin \varphi=U I \sin \beta \cos \alpha
\end{array}\right.
$$

The output current of the shunt unit is

$$
\hat{i_{C}}=\sqrt{(I \cos \alpha-I \cos \varphi)^{2}+(I \sin \varphi)^{2}} \angle\left(-\frac{\pi}{2}-\delta\right)
$$

Where, $\delta=\arctan \frac{\cos \alpha-\cos \varphi}{\sin \varphi}$

The active power and the reactive power of the shunt are

$$
\left\{\begin{array}{l}
P^{\prime}=\left|\hat{u_{L}}\right|\left|\hat{i_{C}}\right| \sin (\delta-\gamma)=U I(1-\cos \beta) \cos \alpha \\
Q^{\prime}=\left|\hat{u_{C}}\right|\left|\hat{i_{L}}\right| \cos (\delta-\gamma)=U I(\sin \alpha-\sin \beta \cos \alpha)
\end{array}\right.
$$

In formula (7) and (9), when providing reactive power to the load, the series unit also outputs active power $P$. At the same time, the phase shift also exists on the PCC. It will cause the active component $P^{\prime}$ in the shunt unit, and $P=P^{\prime}$.

Although active power increases the loss of the system, it accounts for little share of the system capacity. At the same time, it reduces the needed capacity of the shunt unit, and improves the economic benefit.

\section{Simulation result}

In order to verify the proposed control strategy, this section builds the model of UPQC system by Matlab-Simulink. The parameters are shown in Table 1.

Table 1 Parameters of the UPQC system

\begin{tabular}{ccc}
\hline & Parameters & Value \\
\hline & grid phase voltage $\left[u_{s u, v, w} / V\right]$ & 220 \\
& load $[R / \Omega, C / u F]$ & 5,636 \\
veries unit & transformer ratio & 1500 \\
& filter inductor $\left[L_{1 u, v, w} / m H\right]$ & $1: 5$ \\
& filter capacitor $\left[C_{u, v, w} / u F\right]$ & 0.3 \\
carrier frequency $[f / K H z]$ & 10 \\
shunt unit & inductance $\left[L_{2 u, v, w} / \mathrm{mH}\right]$ & 10 \\
& dc-link capacitor $[\mathrm{C} / \mathrm{uF}]$ & 3 \\
& carrier frequency $[\mathrm{f} / \mathrm{KHz}]$ & 5000 \\
\end{tabular}

Under the condition of the stable power grid, the shunt unit holds the dc voltage at $1500 \mathrm{~V}$, and compensates $50 \%$ reactive power of the load demand. The series unit outputs the rest reactive power.

As shown in Fig.6, the series and shunt units are both output reactive current, and the series unit also outputs active power. Because the shunt unit takes the role of regulating dc voltage, it will absorb active power. This could keep the balance of the whole system, and the cooperative compensation 
could improve the power factor.

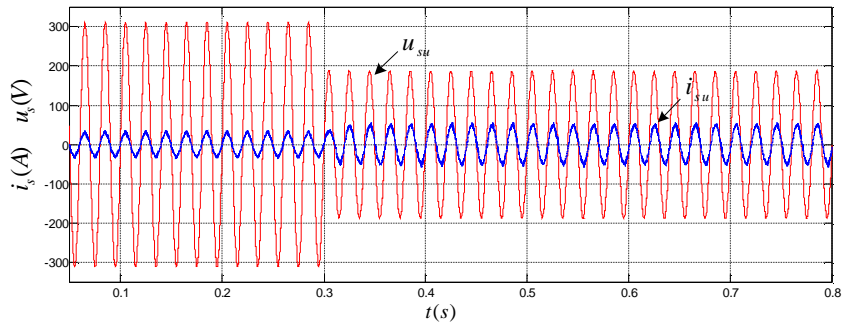

a) Grid voltage and current

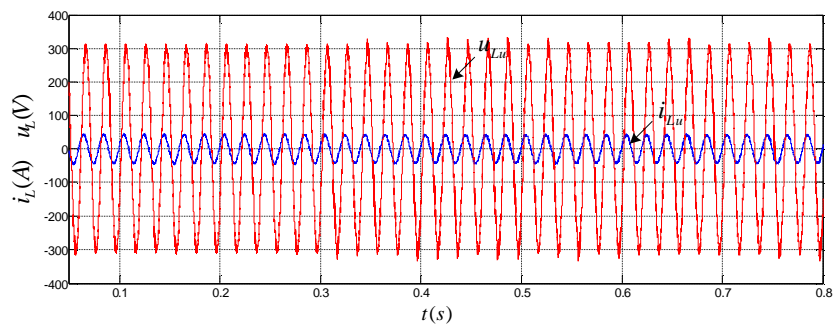

b) Load voltage and current

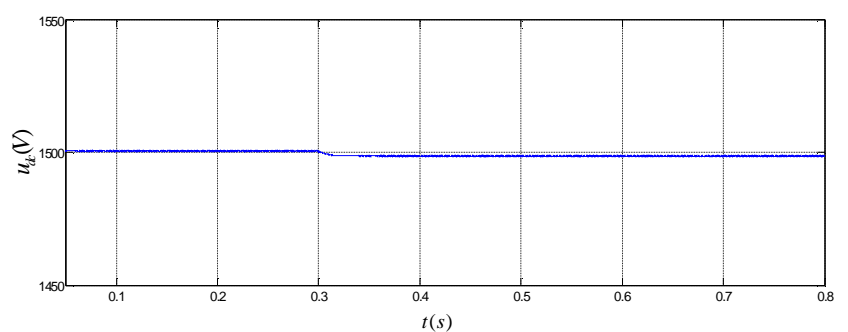

c) dc voltage

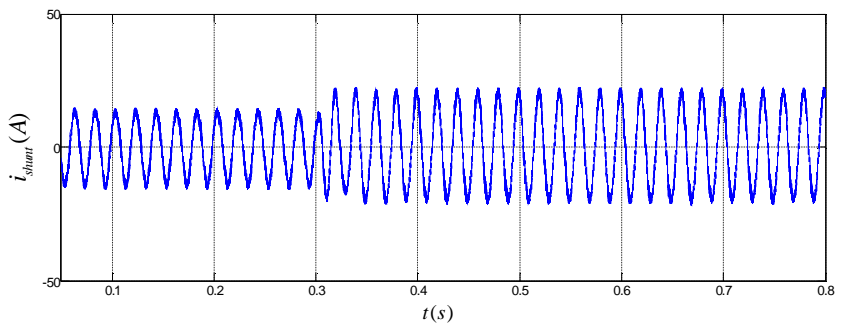

d) The current of the shunt unit outputs

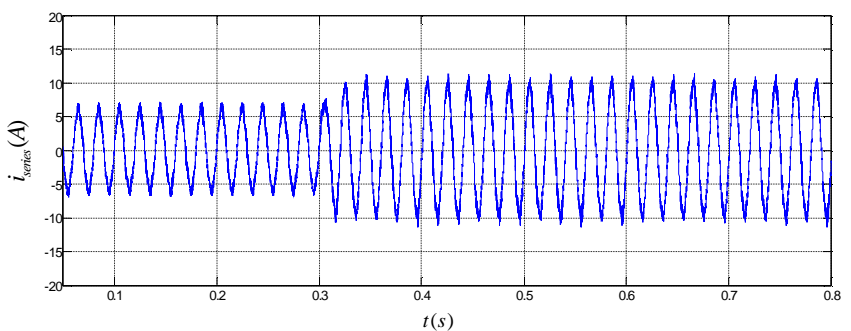

e) The current of the series unit outputs

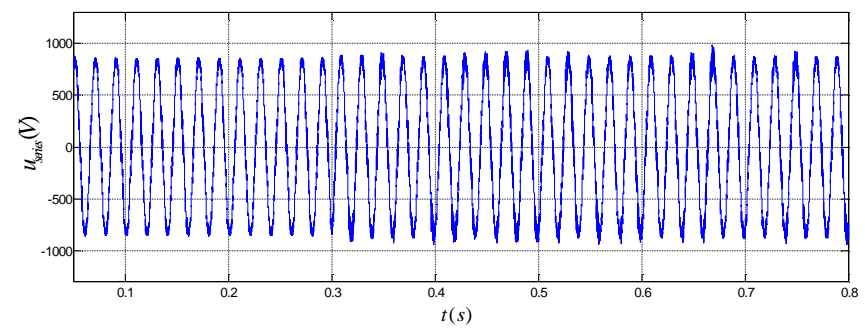

f) The voltage of the series unit outputs

Fig.6 Dynamic performance of the system 
At $0.3 \mathrm{~s}$, the grid voltage falls to $60 \%$. In addition to output reactive current, the series also restores the grid voltage to maintain the load voltage.

From Fig.6, during the grid drop, the series unit could maintain the load voltage at 220V. Under the common efforts of series unit and shunt unit, the power factor of the grid is close to 1 , and the dc voltage can also keep at $1500 \mathrm{~V}$.

According to above analysis, after adding power coordinated control strategy, the series unit not only has the function of holding the load voltage, but also could provide a certain reactive power to the load. Although it can result in the circulation of active power, this strategy has little influence on the system loss. This strategy could lower costs and improve resource utilization.

\section{Conclusion}

In this paper, a strategy of the reactive compensation based on UPQC has been proposed. The active and reactive power decoupling control based on the shunt unit could output the reactive power the load needs and maintain the dc voltage. And the coordinated control based on the series unit also could output a certain active power, and keep the load voltage stable. This strategy can compensate the reactive power effectively, reduce the pressure of the shunt unit, and enhance the utilization.

\section{References}

[1] Vinod Khadkikar. Enhancing Electric Power Quality Using UPQC: A Comprehensive Overview. IEEE Transactions on Power Electronics. vol. 27, no. 5, p.2284-2297, 2011.

[2] H. Akagi, S. Inoue, and T. Yoshii. Control and performance of a transformerless cascade PWM STATCOM with star configuration. IEEE Transactions on Industry Applictions. vol. 43, no. 4, p.1041-1049, Jul./Aug. 2007.

[3] Maharjan, L., Inoue, S., Akagi, H.,Asakura, J.. State-of-Charge (SOC)Balancing Control of a Battery Energy Storage System Based on a Cascade PWM Converter. IEEE Transactions on Power Electronics. vol. 24, no. 6, p.1628-1636, 2009.

[4] C. K. Wan, G. Yang, H. Geng, T. S. Zhang. Control methods of a cascade power regulation system for smart grid. Innovative Smart Grid Technologies Asia, 2011 IEEE PES. P. 1-5, Nov. 2011.

[5] C. Wan, G. Yang, W. Wu, W. Zhang. An active and reactive power regulating system based on a cascaded-converter. The 2nd International Symposium on Power Electronics for Distributed Generation Systems. p.453-458, 2010.

[6] Mori S, Matsunso K etal. Development of a large static Var generator using self-commutated inverters for improving power systems. IEEE Trans Power Systems. vol. 8, no. 1, p.371-377, 2002.

[7] S. S.Choi, B. H. Li, D. M. Vilathgamuwa. Dynamic voltage restoration with minimum energy injection. IEEE Trans. Power Syst., vol. 15, no.1, pp. 51-57, Feb. 2000.

[8] Wu Fuzhuan, Wan Jianru, Shen Hong. Research of control strategy based on the UPQC minimum capacity method. Power System Protection and Control(In Chinese), 2010, 38(11): 1-5.

[9] Xingtian Feng, Zhihua Zhang, Wenzhong Ma, Lixia Zhang. UPQC coordinated control strategy with circulating active power. Information Science, Electronics and Electrical Engineering (ISEEE). vol. 3, pp. 1825-1829, 2014. 